\title{
Assistants, Guides, Collaborators, Friends: The Concealed Figures of Conflict Research
}

\section{Sarah Ann Jenkins}

\begin{abstract}
Recent scholarship has demonstrated an increasing awareness of the need for more grounded, empirical research into the micro-level dynamics of violent contexts. Research in these difficult, dangerous, and potentially violent conflict or post-conflict settings necessitates the formation of new relationships of dependency, and assistants, friends, collaborators, and guides become central figures in the field. However, all too often, these figures are written out of academic accounts and silenced in our analyses. This not only does them a significant disservice, but it also obscures potential biases, complexities, and ethical dilemmas that emerge in the way in which such research is carried out. Drawing upon fieldwork exploring the 2007-2008 Kenyan postelection violence, this paper argues that reliance upon insider- assistants is essential in conflict settings and explores the challenges inherent in these relationships. As researchers become increasingly engaged in micro- level studies of violent contexts, we must interrogate the realities of how our knowledge has been produced and engage in more open and honest discussions of the methodological and ethical challenges of conflict research.
\end{abstract}

\section{Keywords}

conflict research, ethnography, Kenya

\section{Corresponding Author:}

Sarah Ann Jenkins, Coventry University, IV5 Innovation village, Coventry Technology Park, Coventry, CV1 2TL, UK.

Email: sarah.jenkins@coventry.ac.uk 


\section{Introduction}

A few years ago, at a workshop addressing the challenges of conducting fieldwork in difficult and dangerous settings, I was struck by the marked absence of any discussion of research assistants. Their role was dutifully glossed over by my fellow presenters and, in response to my own "confession" that research assistants and the web of social relations in which I was embedded in the field had played a significant role in producing my ethnographic knowledge, one colleague half-jokingly suggested I "be less honest." This reluctance to acknowledge local fieldworkers' influence over research is far from unusual in academic writing, and there is a distinct unwillingness to admit that we do in fact rely on others in the field to help produce our knowledge (Malony and Daniel Hammett 2007, p. 293). In the past there has been very little attention afforded to the various actors who play a role in field research, ${ }^{1}$ and it is only in more recent scholarship that there has been any concerted effort to engage in some form of dialogue interrogating research assistants' involvement. ${ }^{2}$ For the most part, these figures remain "suspiciously absent" from academic accounts (Barley 1983). The impetus to obscure the influence of others over our fieldwork is arguably embedded in the resilient traditions of field research. To admit the need to rely on others is equated with a lack of proficiency, ability, and skill. To concede that others have (re)shaped our carefully configured research designs and mediated our interactions is to confess to "compromised" or "polluted" data (Cons 2014, 376). This is despite the fact that unambiguous individuality in fieldwork is largely an illusion, and almost certain to be converse to most researchers' experience. As Barley sardonically notes in reference to linguistic capability in particular,

The conventional myth seeks to depict the battle-scarred anthropologist as a lone figure wandering into a village, settling in and "picking up the language" in a couple of months. . . . Never mind that this is contrary to all known linguistic experience. (Barley 1983, 44)

These tenets must be urgently reconsidered, particularly given the fact that more and more research is being carried out in difficult, dangerous, and potentially violent settings, ${ }^{3}$ where collaboration and reliance upon local fieldworkers is essential not only for gaining access and building trust but also for ensuring safety and security. Indeed, in an important article, Hoffman and Tarawalley draw attention to the limits of the ideal of marginality in conflict research. They argue that those who are more central to the context or activity under study - rather than those who enjoy a certain critical distance from the context - are often far better positioned to help navigate the research 
setting (Hoffman and Tarawalley 2014). Nevertheless, these "frontline collaborations" bring with them certain ethical and methodological challenges that undoubtedly shape the information that is gathered, and, as the authors suggest, "the real . . . pitfall would be to exclude the realities of access in these situations from the finished ethnographic text" (Hoffman and Tarawalley 2014, 302).

This article, then, builds upon these important insights. It further explores the role local assistants, guides, collaborators, and friends play in conflict research, and it extends the argument by situating these figures within the reflexive process. Since the late 1980s, scholars have been increasingly concerned with the importance of researcher positionality and subjectivity in the construction of ethnographic knowledge, recognizing that the researcher's presence, identity, and emotionality can influence the story that is told. However, those with whom we work and associate in the field also play a significant role in this construction; they too must be considered in a reflexive approach. Their presence shapes who and what information is accessed, their biases affect the research process, and they can influence the researcher's perceptions of, and emotional entanglement, in the field. More than this, though, we seldom extend our reflexive engagements to an ethical interrogation of how our presence might disrupt the social setting and lives of those with whom we associate. Indeed, assistants' entanglement with researchers can affect the dynamics of their own social spheres and "transform [their] relationships with their 'home' in ambiguous and often troubling ways" (Middleton and Cons 2014b, 285). We must interrogate the realities of how our knowledge has been produced, who has been involved in its construction, in what ways, how this affects the stories we tell in our writing, and what ethical and methodological implications it might have for carrying out field research in difficult or dangerous settings. Thus, the article makes three key arguments: First, that the identity and social position of assistants not only shapes patterns of access - opening up some avenues, while closing off others - but also the stories participants tell. Second, that while insider-assistants are key figures in ensuring the safe progression of the research, their advice is influenced by the biases and prejudices of the conflict setting. This makes it very difficult for researchers to distinguish between legitimate security concerns and subjective judgments regarding the feasibility of research in certain areas or with particular groups. Finally, researchers must be more attuned to the ways in which their presence can disrupt the field and transform the social positions and relationships of those with whom they associate.

In this article, I reflect upon my own experiences of researching the local dynamics of ethnic violence in Kenya and I explore both the practical and ethical issues raised by my collaboration with a key research assistant and 
sveral other local fieldworkers. The article provides a discusison of the possibilities and limitations, the opportunities and challenges, and the prospects and dilemmas that are inherent in the researcher-assistant relationship. It begins by examining the nature of local fieldworker roles in my own research, before reflecting upon the ways in which these figures influenced the data gathered, particularly in terms of trust-building and access. It goes on to explore how assistants can shape researchers' perspectives of and approaches to the field, with a particular focus on safety and security, and concludes by examining how assistants' relationships with researchers can disrupt the dynamics of their own social position and setting. The researcher-assistant relationship is central to conflict research and should not be obscured from academic writing for fear of disciplinary censure; rather, it should become a central component of the reflexive process.

\section{The Multifarious Roles of Hassan and Other Local Fieldworkers}

$\mathrm{My} \mathrm{PhD}$ research sought to explore the micro-level dynamics of ethnic violence, to elucidate who participates in times of conflict, why, in what ways, and how this can be understood in the context of everyday social relations. Focusing upon the 2007-2008 postelection crisis in Kenya, I carried out narrative-style interviews and observed everyday life in the slums and periurban settlements of three Kenyan cities between October 2009 and August 2010. The research-already sensitive in nature by virtue of its interest in individual experiences of, and participation in, violence - was conducted in a delicate setting, less than two years after the cessation of violence, and amidst ongoing political reform efforts and transitional justice mechanisms. In order to negotiate this postconflict, deeply divided environment, I soon came to realize that the use of a research assistant and a number of other local fieldworkers was essential.

I had not intended to work with an "assistant" as such, nor did I anticipate the level of involvement this figure would come to occupy in the project. However, after being introduced to Hassan ${ }^{4}$ - an unemployed Nubian youth from Nairobi's Kibera slum - and after having worked with him for a short while, I realized that he would be invaluable to facilitating the research. Hassan, like many of my interviewees, was an unemployed youth existing on the margins of society, engaging in various activities - both legal and not so legal - to make his daily bread. As a result of previous experience in illicit activities, he had a penchant for discretion and an uncanny ability either to avoid trouble or to talk his way out of it when it found him. He was both charming and astute, able to form friendships very quickly and to put people 
in his company at ease. He was, at the same time, a stubborn, manipulative, and rather paranoid character who was highly suspicious of others, including myself at times. These aspects of his character made working with him both extremely easy and extremely difficult, and undoubtedly affected our approach to the field in both positive and negative ways.

After a few weeks of working with him, I offered Hassan a weekly salary and he became my almost constant companion. Initially, he acted as a guide and key informant in Kibera, showing me around the settlement and talking freely about ethnicity and politics in Kenya. His role became increasingly complex over time, however, as he began to traverse the spaces between assistant, guide, collaborator, and friend. ${ }^{5}$ Not only did he manage the practicalities and logistics of the project, organizing travel and accommodation for field sites away from Nairobi, and recruiting local fieldworkers to help us navigate each area, but he also assumed a more collaborative role. He became increasingly involved in discussions over the design of the research, advising in issues relating to access and security; he began to act as a translator in interviews as we came to realize that respondents were able to offer far more detailed personal stories when they were able to speak in Swahili rather than English; he often took the lead in building up rapport with interviewees, his partial-insider status and his charming personality facilitating ease and openness of conversation; and he began to offer analytical input, asking occasional questions in interviews. We had frequent discussions about the progress of the research, talking about what was working and what was not, and, after reflecting upon these conversations, I frequently made alterations to the research design and implementation in response to changing contexts. More than this, though, Hassan became a close friend whose company I, for the most part, very much enjoyed, and who facilitated my integration into social networks both in Nairobi and upcountry.

In addition to working closely with Hassan, I employed a number of local fieldworkers for short periods of time to help us navigate the neighborhoods and small territories of each individual field site. While Hassan was regarded as an "insider" in that he himself participated in the postelection violence and was a resident of an urban slum, he was simultaneously an outsider beyond the confines of Kibera, unaware of local dynamics and contexts, and unable to carry the social capital necessary to build sufficient trust with communities directly in a short space of time. We thus recruited local fieldworkers in each neighborhood of each slum, ensuring that the fieldworker's ethnic identity and personality allowed for the mobilization of local residents. These fieldworkers also advised on issues of safety and security in the area; on occasion they would translate interviews that needed to be undertaken in the local vernacular language, and in some cases, they became a part of our social friendship networks 
in the area. As such, they too elude a clear and definitive label, operating variously as assistants, translators, guides, and friends. Thus, Hassan and other local fieldworkers took on multifarious roles, and their various involvements had significant effects upon the research. The data collected is as much a product of their interactions with and presence in the field, as it is mine.

\section{Opening Windows, Closing Doors: Assistants, Access and Trust in Divided, Post-conflict Societies}

It is widely acknowledged that outsider researchers face greater challenges in terms of establishing trust and accessing the field than their insider counterparts. The latter are able to mobilize their preexisting social networks, have a greater proficiency in the language, and enjoy a more nuanced familiarity with the local social and political context (Smyth 2005, 17). All of this engenders quick and easy entry into the community and ensures that the researcher is seldom regarded with deep suspicion. The difficulties encountered by outsider researchers, on the other hand, while not limited to sensitive or difficult research, are certainly amplified by it. Questions are frequently raised concerning the researcher's identity and intent, and the suspicion with which they are often confronted can create serious problems.

In this section, I argue that through collaborative partnerships with local fieldworkers and assistants, these challenges can be navigated and managed, and that "the success of field researchers is determined in large part by their ability to develop trust with local counterparts" (Mertus 2009, 3). However, there are drawbacks to these partnerships; they can have negative effects on how the researcher is perceived, and they can, somewhat paradoxically, actually close down avenues of access and information in ways that are not always immediately apparent. Indeed, Berreman's seminal text Behind Many Masks - one of the first articles to address the use of field assistants - draws acute attention to this issue. In his research in a Himalayan village, Berreman's unscheduled transition from a Brahmin to a Muslim assistant opened up access to previously impenetrable low-caste communities and uncovered previously concealed information. However, this relationship simultaneously closed off his former access to high-caste groups (Berreman 2012). Thus, in order to reveal potential biases in our research, and to better understand the factors affecting the production of knowledge, it is important to reflect critically on the positionality of local fieldworkers and on how their involvement might influence the mobilization of participants and the stories they tell.

Many, if not most, scholars highlight the importance of trust in mobilizing research participants, and while some level of trust is essential in all disciplines, 
its importance is further accentuated in sensitive or difficult settings. Studies of deviant behavior, from domestic violence to organized crime, institutional corruption to large-scale conflict, are often regarded with unease and suspicion by researched communities, and researchers frequently encounter the accusation that they are spies. Sluka suggests that "it is difficult to find an anthropologist who has done fieldwork who has not encountered this suspicion" $(1995,283)$, and it can have serious implications for the willingness of individuals to participate in the research. The somewhat unfortunate timing of my own fieldwork only served to inflame such rumors. Throughout the duration of my time in Kenya, the International Criminal Court (ICC) Chief Prosecutor, Luis Moreno Ocampo, was conducting investigations in the country and building a case against key figures suspected of organizing and funding the postelection violence. During this period, key steps toward the consolidation of a prosecution case were taken, Ocampo himself made two official visits to the country, and media attention remained high. In short, the investigations of the ICC were continuing in a decidedly visible manner and they were the topic of much conversation and debate among people at the local level. As such, an outsider researcher asking questions about the details of the violence was bound to raise some gossip and chatter. Rumors that I was a government spy, a CIA agent, an ICC investigator and, most perplexingly, Ocampo's niece, proliferated in my field sites, making some individuals and communities uneasy about participating in the research. The source of their fears varied. Some believed that the ICC was looking to build cases against ordinary people; some feared reprisals from neighbors who had been heavily involved in the violence; and some were concerned that members of their ethnic group would accuse them of betraying the community by assisting the ICC in developing a case against their ethnic political leader. These fears concerning my identity and intentions needed to be allayed and some level of trust established for the research to proceed, and for it to do so safely.

It is often assumed that sufficient trust can only be developed over an extended period of time - a "sustained trust period" (Norman 2009, 86) between the researcher and the researched - and as such, ethnographic methods are highly suited to sensitive research. Brewer, for example, states:

Ethnographic research has special qualities suited to dealing with controversial topics in sensitive locations. . . . To be successful . . . ethnographic research demands considerable time commitment. This is true especially with sensitive topics where the researcher's penetration into the field takes longer and, once successful, continually needs to be reinforced by intensive contact. (Brewer 1993, 130-31) 
Such techniques seem to require a near-exclusive engagement with a localized, bounded geographical space in order to allow sufficient time for trust to develop, rendering problematic any research that needs to move in and out of field sites more quickly. My own research sought to identify and understand variations in violence dynamics across a number of field sites, and consequently could not support such time commitment in one place. However, through collaborative partnerships with local fieldworkers, a different form of trust relationship can be fostered that depends less on the researcherresearched relationship and more on that between the local fieldworker and their community. That is to say, the researcher can establish and utilize networks of trust through partnerships with insider assistants. Many researchers make mention of the importance of having an insider to "vouch for who you are and what you're doing" (Jacobs 2006, 159), but the implications of this are seldom explored in detail. Sixmith et al., for example, suggest that the introduction from fellow community members can foster the perception of the researcher as "a friend of a friend" $(2013,584)$. Strocka similarly declares that his own attempts at accessing youth gangs in Peru were largely unsuccessful until he was introduced to Daniel, a former gang leader who became his assistant (Strocka 2008, 262). Indeed gaining the trust of an insider, with an already established "trustworthy and legitimate social network" (Chavez 2008,482 ) leads to an extension of that trust to the researcher.

Access to field sites and the mobilization of participants in my own field research was, in the first instance, highly dependent upon the trust that had been built over intensive interaction with Hassan. In Nairobi and Nakuru, Hassan's friendship networks or family connections provided an initial relationship with a local contact in each overarching field site, and this was soon extended to individuals in the various neighborhoods under study, to their social networks, and to the local communities in general. In Eldoret, where we had few prior contacts, Hassan's charismatic, outgoing, and likeable personality was of fundamental importance in establishing friendships with local people. In the first week, he spent time meeting people in Eldoret town, establishing rapport with local market vendors and their customers. He would sit and chew miraa with two individuals in particular, spending long hours of the day talking with them. By "hanging out" with these individuals, engaging them in honest, open, and free conversation, we were able to develop friendships quickly, and to utilize these social networks to gain access to field sites around the town. Hassan's partial insider status ensured that initial suspicions concerning my intent were somewhat allayed and my own openness about my research further established a foundation of trust. Thus, by fostering trust with a small number of insiders, the researcher can establish "trust by association" (Norman 2009, 79) in a much shorter space of time. 
When access is so heavily dependent on an individual or a small group of individuals, however, perceptions of the researcher become inextricably linked to the characteristics of these figures. These perceptions can work in positive ways, particularly in places where the local fieldworker is very popular, and they can open up access to otherwise inaccessible groups or information. However, equally and often concurrently, they can close down other avenues. In a deeply divided society such as Kenya, and particularly one that has experienced recent violence, the ethnic identity of assistants can be extremely important and can significantly influence the mobilization of participants and the stories they tell. In my own research, Hassan's Nubian identity was fortuitous in terms of his perceived neutrality on the subject at hand. His community's relatively small size, its concentration in Nairobi, and its lack of significant representation at the highest levels of political competition meant that his political leanings were not immediately assumed, and he was seen to be largely impartial to the events under discussion. This facilitated the initial trust-building phase in each field site and enabled open and free conversation during the interviews themselves. A research assistant from one of the larger ethnic groups, whose community had been highly active during the violence across the country, would have been unable to straddle the ethnically diverse neighborhoods of the numerous field sites to the same extent or effect as Hassan.

The ethnic identity of local fieldworkers, however, had to be very carefully considered, particularly in neighborhoods with clear majority communities. In all sites, it was vital that local fieldworkers were popular and able to mobilize participants who reflected the demography of the area. In ethnic enclaves, however, local fieldworkers almost always needed to be members of the dominant community; indeed, collaborating with members of minority communities in these ethnicized spaces proved to be highly problematic. During the course of my fieldwork, there was only one occasion where we attempted to access the site through members of a minority community, and this decision played a significant role in rendering the site unworkable. Utilizing family contacts of a friend in Nairobi, we approached the Kalenjindominated village of Maili Nne, Eldoret, through a Luhya family. Given the fact that minority communities in the village had been targets of threat, intimidation, and violent eviction during the crisis, entering the field site through the "victims" of the violence in the area inflamed suspicions that I was building a case against the majority group and constructing a demonizing narrative. By virtue of the topic under study, the levels of trust between the local fieldworker and the community were not high enough for the "trust by association" technique to be effective. This was not only an obstacle in terms of mobilizing participants and their willingness to talk openly about the 
crisis, but it also created tensions between the local fieldworkers and their community, as the latter began to accuse them of working with the ICC, thus raising ethical issues as well as methodological challenges. After two days this, in addition to a number of other problems, led us to abandon the field site.

The effect of my association with local fieldworkers in this instance was particularly transparent; it visibly closed off access to certain information and to key groups in the community as people refused to participate, or offered only single-sentence responses to questions. The consequences of researchers' associations with others in the field, however, are not always as clear and the research can be influenced by our relationships in more subtle, but no less significant, ways. Interpersonal hostilities and tensions that might exist below the surface between local fieldworkers and certain members of their community, for example, can either limit access to particular people, or can influence the information provided in interviews. One such example that came to light during my research was in Kiambaa, Eldoret, where, on January 1, 2008, between seventeen and thirty-five Kikuyu men, women, and children were burnt to death in a church by Kalenjin groups from neighboring villages. On our last day in the site, our local fieldworker, a young Kikuyu man named Kamau, took us to one of the few Kalenjin families living in the village. The father of the household, it transpired, had been accused of participating in the burning of the church, and of looting his neighbors' properties; he had been arrested in the immediate aftermath of the crisis but had since been released. During my interviews with the mother and her two adult children, they each used the interview to defend the father's innocence, insisting that he had not participated in the incident in any way and that he had fled the village with the family on the day of the attack. As we walked away, Kamau bitterly exclaimed that he had seen his TV, sofa, and table in the family's house, claiming that they had been stolen during the postelection violence; he recounted that he had given evidence to the police regarding the family's involvement. Indeed, Kamau asserted that he had wanted to take me to this family, in part, to show them that he had not forgotten their actions during the crisis. Thus, there were persisting personal hostilities on both sides of the relationship, and by virtue of "hanging out" with Kamau and being introduced to the family through this individual, I was perceived to be "on his side." As Thomson notes, "research assistants can influence the neutrality and objectivity of participants" $(2010,28)$. Thus, while in this case access was not constrained by my association with Kamau, the interpersonal history between him and my interviewees - in addition to the broader interethnic hostilities at work-certainly shaped their response to me and informed the narrative they told. 
Constraints upon access and open communication with interviewees are not only affected by the researcher-assistant relationship but also by other figures with whom the researcher associates. Friends and acquaintances that the researcher is seen with, for example, can influence the community's perceptions. In the first few weeks of my research in Kibera, a friend of Hassan's - a Kikuyu youth named Mwangi-often followed us around the slum as we walked through the various villages. His presence and the perceived closeness of our relationship with this youth, however, caused significant problems in the Luo-dominated neighborhood of Gatuikera. Mwangi was well known as a key supporter of the predominantly Kikuyu Party of National Unity in 2007, campaigning against the Luo's preferred Orange Democratic Movement party, and, consequently, he was not well liked in the area. Moreover, he had apparently appeared on national television during the crisis, accusing a prominent youth group from Gatuikera of launching an attack on his house and chasing him away from the area-an assertion that turned out to be not entirely accurate. While the group had been key participants in the violence, they claimed that Mwangi had fled the area immediately after the announcement and that nobody had chased him away. By his own admission, Mwangi had exaggerated his story to the news reporters in order to demonize the Luo community and to incite fellow Kikuyu to fight back.

Thus, there were deep personal resentments between him and the youth in Gatuikera. My association with Mwangi cast me in a negative light with these gatekeepers of the Luo community, and I was deeply distrusted. Indeed, the youth group effectively closed off our access to residents of this village for a time. It was only after detaching from Mwangi for a while that some low levels of trust could be built that would facilitate some level of access to the community. Thus, just as access can be opened up through perceptions of the researcher as a friend of a friend, they can be just as easily closed down by a "friend of an enemy" framework. As Malony and Hammett note, research assistants and others with whom the researcher associates can, at least at first, frustrate research efforts with particular segments of the community as "existing hostilities [are] conferred upon the researcher through their association" (2007, 296). Hannah Gill similarly notes that, in her research, "simply by choosing to live with a particular household I had inadvertently made my alliance, limiting whom I could visit and where I could go" (Gill 2004, 5-6). The researcher may not always be aware of these social dynamics, particularly in the initial phases of fieldwork.

Thus, the use of research assistants and local fieldworkers to mobilize participants not only shapes who can be accessed, but also what stories might, or might not, be told. As David Holmberg noted in connection to his own 
fieldwork, the relationships that he engaged in in the field "had an effect on how people responded to me, but also entangled me and situated me in ways that sometimes hampered access or kept me from learning things" (Holmberg 2014, 318). Rather than obscure potential biases in our research as a result of our interactions with others, we must honestly engage with and reflect upon who and what information we were able to access, whose voices might have been silenced and for what reasons, and how the relationships and friendships we engage in might affect the stories we are able to tell. That is to say, it is, in part, "a question of ... what will they tell me given how access was obtained" (Campbell et al. 2006, 117).

\section{Ensuring Safety, Constructing Fear}

The rising interest in understanding cultures of violence, coupled with the increasing number of scholars conducting research in sensitive, difficult, and dangerous settings, has drawn attention to the practical and ethical limitations of existing field research practices. As Middleton and Cons point out, these fresh areas of ethnographic interest have necessitated the cultivation of new forms of field relationships in order for researchers to navigate these settings safely (Middleton and Cons 2014b, 281). The research assistant becomes a central and integral figure in these contexts of insecurity. This section considers the benefits - and indeed the necessity — of collaborating with insider assistants in unstable and potentially dangerous field environments, drawing attention to the tensions and dilemmas this raises with existing ethical practices. It then discusses the drawbacks of this dependency in relation to my own fieldwork.

Existing ethical guidelines and principles of responsibility maintain that researchers are responsible for ensuring the safety and security of both themselves and those with whom they associate in the field. However, in potentially dangerous settings, this premise is highly problematic. Not only does it assume that the researcher is aware of and, indeed, fully capable of anticipating all the potential risks of the research, but it also implies that he or she has absolute control over the research environment. These assumptions are deeply misleading and generate serious dilemmas for researchers as their negotiation of the field comes into tension with some of the presuppositions of existing guidelines. Outsider researchers face considerable problems identifying and anticipating the potential dangers of their fieldwork because of their "relative lack of knowledge of the context and relative inability to interpret cues" (Smyth 2005, 17). Consequently, they must engage in a collaborative partnership with insider-assistants who can facilitate their safe navigation of the field. 
Several researchers have drawn attention to the importance and centrality of insiders in their own fieldwork, suggesting that their advice and very presence was essential to maneuvering around the field safely and successfully. Nordstrom, for example, states that "the foresight of those around me protected me from physical violence I had not anticipated" (Nordstrom 1997, xvii). Toros similarly declares that her safety lay in the hands of her interviewees. She claims that "they know the territory, the risks and the best way to carry out my research without getting anyone else hurt" (Toros 2008, 287). In my own field experience, while I had anticipated that the sensitivity of the topic could present risks, I not only misunderstood the nature of those risks, but I was also ignorant of the best strategies to circumvent or minimize them. I had assumed that the greatest risk was the prospect of my data being of interest to local authorities and that it was crucial to develop strategies to protect participants' anonymity and confidentiality. However, I had not anticipated much hostility from members of the researched communities themselves. In hindsight, this was extremely naïve and, as it turned out, these hostilities posed the greatest physical threat to myself, my field assistants, and my interviewees. Moreover, these dangers were not stable, but rather varied across time and space, making it very difficult for me to develop a clear understanding of when and where the risks were greatest.

Kovats-Bernat suggests a "reconfiguration of how we perceive our relationship with our informants" to one of "mutual responsibility" rather than clinging to the erroneous assumption that the researcher is capable of foreseeing 'the deadly consequences of participation" (Kovats-Bernat 2002, 7); this notion of collaborative responsibility is a far closer approximation of my own experience in the field. In order to ensure the safety of all involved, Hassan, my local fieldworkers and other friends and contacts I made played a significant role in shaping, redefining, and altering the ways in which the research was carried out. They assumed a prominent, and often a leading, role in three key aspects of the fieldwork: choice of field sites, strategies for navigating sites and approaching interviewees, and managing how the research was being perceived.

The notion that our carefully considered research designs and case selections might be influenced by those we meet in the field sits rather uncomfortably with the foundations of scholarly, scientific analysis. However, in contexts of insecurity and potential violence, it is not always possible to follow our plans to the letter, and oftentimes we must heed the advice of others in the choice of where we carry out our research. Prior to arriving in the field, and after a close reading of open source material describing the dynamics of the violence, I had identified three overarching field sites and a number of villages and slums in these areas in which I wanted to work. However, 
throughout the fieldwork, discussions with Hassan and other local contacts in each area, at times, led me to adjust these choices. For example, I was eager to work in Turbo, a town on the outskirts of Eldoret. It was a hotspot of the violence and the hometown of the prominent Kalenjin politician MP, William Ruto. Many of our local contacts in Eldoret expressed significant hesitation over this, so Hassan went to Turbo with a youth from the area to assess the situation. He returned to tell me that the research was far too sensitive in the area and that it would be impossible to carry it out without putting ourselves and any participants at risk. Throughout my fieldwork, people within my social networks warned me away from some field sites and, after discussing my research objectives with them, they advised me to work in places that I had not previously considered; for the most part, I followed their suggestions. Indeed, I believed it would be reckless and imprudent - or as Toros puts it, "dangerous and arrogant" $(2008,287)$ - to ignore the advice provided in relation to safety, security, and the choice of field sites. Thus, my assistants and other local contacts not only assumed a significant amount of responsibility in terms of protecting me and my participants from potentially dangerous situations, but it was also necessary for me to relinquish some control over the research design in order for them to do so.

The second key role my local fieldworkers took on in relation to security issues was advising me of the best ways to approach and navigate each individual field site, and they sometimes made suggestions regarding how to present the research or pose questions to particular individuals or groups. For example, I was advised to omit questions about payment for or organization of violence when interviewing members of the Kalenjin community in villages surrounding Eldoret. As Turner points out, "research assistants themselves are often better placed to identify the most appropriate way to conduct an interview" $(2010,214)$. Each individual field site necessitated different ways of moving around and carrying out the research. While in some places we were able to walk around quite freely and interview people in open spaces, in other sites we needed to establish a base — such as a residential house - and to move around the area with more discretion. I was often not party to these decisions, but rather they were made "behind the scenes" by my assistants.

In the initial phases of the research, my assistants had, quite independently, assumed significant responsibility for ensuring the safety and security of those involved in the research. However, by taking on this leading role, they had a tendency to develop strategies without explaining them to me, and some of the strategies they employed raised ethical problems. It was clear on a few occasions, for instance, that local fieldworkers had deceived some interviewees about the nature of the research, not only to entice their participation, but also to preempt suspicions of ICC involvement. For example, in 
Nakuru, I discovered that a local fieldworker had told a youth who had been very actively involved in the violence that I was a director making a film about the crisis and that I wanted to hear his story in particular. He believed that this flattery and the prospects of some future paid involvement with a film would ensure the youth's discretion, preclude any suspicions as to my intent, and prevent any hostile reaction from him and the rest of his gang. While I insisted that complete honesty and openness regarding my intentions was essential, there were occasions when my assistants omitted to tell me about certain strategies they adopted for navigating the field. Townsend Middleton relates a similar experience of his research assistant manipulating the presentation of the research to interviewees, and he reflects upon the ethical dilemmas this raised for him:

I would not have condoned such deception. But neither did I interrogate Eklavya too deeply on his behind the scenes tactics. How much due diligence was really due? (Middleton and Pradhan 2014, 368)

Thus, when assistants and fieldworkers assume responsibility for aspects of the fieldwork, their initiatives and backstage tactics can be ethically problematic, despite the researcher's attempts to control this.

The third, and arguably most crucial, way in which local fieldworkers ensured the safe progress of my research was by monitoring emerging threats, and by evaluating how the research and I were being perceived.

Every field-worker runs across a good deal of gossip, hearsay, slander, rumor and even character assassination, but they acquire inordinate importance in violent situations in which access to such information can make the difference between life and death, safety and injury. (Robben and Nordstrom 1995, 15) ${ }^{6}$

In my own experience our awareness of potentially dangerous rumors among researched communities was almost entirely dependent upon local fieldworkers and friends in the area. These local contacts were often able to manage these rumors, reassuring people and assuaging fears of my involvement with the ICC, for example. However, there were a few occasions where they were unable to stem rising concerns, and it was their quick responses that ensured a safe retreat from the field site. For example, in Nakuru, we spent a week working in Pondamali. There were some initial concerns about local gangs' reactions to the research and some quite stringent tactics were adopted to limit my visibility in the area. For example, we would change the base for our interviews each day, and entered and exited the slum by different routes each morning and evening. However, as the week progressed and word spread 
around the neighborhood that I was carrying out interviews relating to the postelection violence, increasingly dangerous rumors began to proliferate. Our local fieldworker was able to manage these for the first few days, laughing off suggestions that I was an undercover ICC investigator and that I had a camera hidden in my glasses. However, on the penultimate day of our research in this area, as I was conducting an interview together with Hassan, we received a phone call from the fieldworker. He explained that the local youth were gathering together and organizing to come and attack us, shouting, "That ICC girl has come to take us all to the Hague!" We hastily left the field site. Without our local contact monitoring local gossip and observing how people in the neighborhood were reacting to the research, we would not have been aware of these developments and could have endangered ourselves and our interviewees.

It should be noted here that the patriarchal nature of Kenyan society and the gender dynamics of my field relationships not only amplified the sense of responsibility my assistants adopted in terms of ensuring my security, but also compounded problems in trying to control the tactics of local assistants. As a young, female researcher, my assistants and local fieldworkers adopted a very protective stance with regard to my security and it was not uncommon for Hassan to profess, "What will I tell your mother or your father if something happens to you? If something happens to their daughter, what will I say?" It seems likely that my assistants were more cautious than they perhaps would have been with a male researcher, and I suspect that they did not actively communicate their tactics to me in the same way that they would have had I been male. More than this, though, these gender dynamics made discussions over the importance of ethical practice and any criticisms of particular tactics far more difficult and sensitive.

Nevertheless, from informing choices in field sites to developing strategies for discrete movement around dangerous neighborhoods, from advising on the way to frame questions to certain individuals and groups, to monitoring how the research was being perceived by local communities, my assistant and local fieldworkers took the lead in ensuring the safety of all involved in the research. Researchers in dangerous settings do not have absolute control over the field, and sometimes the researcher's "agency paradoxically depends ... on the suspension of that very agency to the agency of others, including assistants" (Holmberg 2014, 314).

However, while negotiating difficult and potentially violent settings necessitates some degree of collaboration with insider assistants, the dependency upon their advice and perspective does have substantial drawbacks and can affect the researcher's approach to the field in quite significant ways. Assistants, it must be remembered, are encumbered by their own positionality, 
just as researchers themselves are, and consequently they bring their own personal biases and prejudices to the research. In sensitive and potentially violent field settings, it is often difficult for the researcher to dissociate the broader societal prejudices in which the assistant and other local contacts are embedded, from more legitimate concerns regarding threat and danger. Indeed, in a context of pervasive fear, insecurity, and distrust, local anxieties can, to a certain extent, be transferred to the researcher, altering the way in which they perceive and approach the field.

In my own research, the Kalenjin community in and around Eldoret were the subject of deep distrust and fear among other communities, both those living in the area, and those from elsewhere in Kenya. I was repeatedly warned that working in Kalenjin villages surrounding Eldoret and questioning residents about the postelection violence would be too dangerous. Hassan, in particular, was extremely reluctant to even attempt to penetrate these spaces; he had no social contacts in these areas, and held his own prejudices about the group, labeling them as "secretive, backward, war-lovers." These perceptions were only further confirmed by residents of the other neighborhoods in the area, and they repeatedly discouraged us from attempting to access neighboring Kalenjin villages. While my academic desire to work in these areas had not diminished, I began to feel anxious and uncertain about the potential consequences, particularly in light of reports that ICC investigators had been attacked in recent months in these areas.

After about a month of being in Eldoret, I managed to make contact with a British student who had been involved in a school development project in Nandi Hills, a village approximately $40 \mathrm{~km}$ outside of Eldoret. I decided to travel up there to assess the prospects of carrying out research in the area. Hassan refused to come along, so I went alone to meet with my contact. However, the doubts of Hassan and others played upon my mind throughout the journey, and I arrived in the town deeply anxious, paranoid, and nervous. I met with my contact and some Kalenjin friends of his in a local bar where we began to discuss my research. I was extremely cautious in these conversations, skirting around my project's primary focus upon the local-level dynamics of violence, and reframing the research in order to emphasize issues of the deep historical injustices in Kenya and their impact upon democracy and the election process. I perceived a level of discomfort among the youths present, and when my initial contact began to describe my research more directly, I sensed apprehension and misgiving - if not hostility - and the conversation was very quickly changed. In other field sites, I may have attempted to speak privately with one of the youths to explain the research more openly and in more detail. However, the voices of my assistants resounded in my head and, in effect, I had adopted their own prejudices and fears of broaching the subject 
among this community. Consequently, I was overly cautious in my attempts to access the site.

Similar apprehensions influenced my interviews with certain individuals and gang members whenever assistants, local fieldworkers, or friends had expressed fears or misgivings. For example, when interviewees were identified to me as members of the Mungiki sect - or as members of a notoriously violent gang - I often approached the interview far more cautiously, sometimes reframing particular questions, avoiding others, and not calling attention to contradictions or inconsistencies in their narratives as frequently or intently. Punch warns that researchers must not "become over-sensitive so as to avoid dubbing the setting or topic virtually unresearchable" (Punch $1989,181)$. While this is undoubtedly true, it is often difficult for outsider researchers to discern a legitimate security concern from a subjective judgment embedded in complex social dynamics. The advice of local fieldworkers in terms of how and where to carry out research is embedded in their own positionality, and consequently issues of security can become colored by particular perspectives. By beginning the research in Nairobi, and by taking on Hassan as my research assistant, I had inadvertently-yet significantly-influenced the groups that I would most associate with and take advice from. Perceptions of the Kalenjin as secretive and war-like and the Mungiki as suspicious and unforgiving were pervasive among other communities in Kenya, and almost all contacts and interviewees expressed significant apprehension about my conducting research with members of these groups. While I sought to assess the veracity of these concerns through conversations with as many people as possible, the overwhelming sense of trepidation was difficult to ignore and I became entangled in the culture of fear that pervaded the social context. While Susan Thomson (2010) is right in suggesting that well-prepared researchers should be able to identify the biased positions of assistants and others with whom they associate, she underplays the emotionality of field research and the difficulties in distinguishing rational security concerns from socially embedded biases. In so doing, she implies that fear and security concerns are easily overcome. This is not always the case, and consequently, it is important to pay attention to the emotions that do emerge in the field and to reflect upon how they might affect the knowledge we produce. As Widdowfield notes,

Not only are emotions an inherent and integral part of conducting research, but emotions can have a real and tangible impact on the research process. In particular, emotions may affect the way, or indeed whether a particular piece of research is carried out. (Widdowfield 2000, 201) 


\title{
Disrupting the Field: The Dangers, Dilemmas and Consequences of the Researcher-Assistant Relationship
}

Within the researcher-assistant relationship, there are inherent tensions, shifting power dynamics, and a challenging "politics of [mutual] dependency" (Cons 2014, 390). It is important to explore these dynamics, not only because they can influence the way in which we approach the field and the knowledge we produce but also because they are revealing of the currently silenced realities of contemporary conflict research. More than this, however, our associations with research assistants can affect their social positions and relationships in significant ways, thus drawing attention to the ethical dimensions of working in collaboration with local fieldworkers. We must be far more attuned to the challenges and consequences research assistants face through their relationships with us and take any possible measures to minimize these negative effects. As Stacey notes,

\begin{abstract}
No matter how welcome, even enjoyable the fieldworker's presence may appear to "natives," fieldwork represents an intrusion and intervention into a system of relationships, a system of relationships that the researcher is far freer than the researched to leave. The inequality and potential treacherousness of this relationship seems inescapable. (Stacey 1988, 23)
\end{abstract}

Many, if not most, of the challenges faced by my research assistants and local fieldworkers had their roots in the vast financial disparities between myself and the context in which I was embedded. In settings where the financial asymmetries and inequalities between the researcher's world and that of the researched is painfully apparent, hiring local people as assistants and guides is often, at least in part, rationalized by researchers as a charitable act or a form of reciprocity. Undoubtedly, there are clear benefits of a steady income for research assistants, and a regular salary can provide a degree of financial security, particularly if it is received over an extended period of time. Indeed, the consciousness of the "philanthropic" nature (Maloney and Hammett 2007, 296) of the relationship can lead to underlying expectations of gratitude on the part of the researcher. In their dramatization of the researcher-assistant relationship, Ajwang' and Edmonson draw attention to this expectation by having the character of the researcher exclaim, "I just thought you'd be ... grateful," when the assistant figure did not express the anticipated level of enthusiasm for the negotiated salary (Ajwang' and Edmondson 2003, 473). However, the assumption that the receipt of a generous salary is unproblematic and that it has wholly positive consequences is 
misguided. In my own fieldwork, Hassan and other local fieldworkers soon felt the more negative implications of being employed by a "rich," white, female researcher.

While the salary I offered to local fieldworkers was generous by local standards, it certainly was not excessive. Despite this, however, many of my assistants' families and friends assumed that the financial rewards were far more considerable, and soon began to demand a share in the "good fortune." All of my field assistants were subject to increasing demands from family, friends, and members of their communities. For the most part, these tended to take the form of subtle, small-scale or light-hearted requests, such as buying soda or miraa for the group. It was not uncommon for people in Hassan's village to call across the street asking him to buy them one thing or another, and most of my assistants had to tolerate jokes that they were now "sitting on millions." Other members of the community would pressure my assistants to bring me to their homes for tea or to make sure I attended their fundraising event. While these were often gestures of friendship, kindness, and hospitality, on occasion they were deemed by my assistants - and myself - to be more self-serving. That is to say, that some individuals saw me as an easy opportunity to obtain money and would accuse my assistants of selfishly keeping me to themselves.

At first, these various demands seemed to be relatively minor annoyances, and though tiresome and wearing, largely innocuous. However, it soon became clear that they needed to be considered carefully and managed effectively in order for Hassan not only to maintain his friendship networks but also to remain included in important social relationships of reciprocity and assistance. Several scholars have identified that social networks in impoverished urban settings function as a form of social capital and that friends, neighbors, and family members are expected to assist each other in mitigating economic and social crises whenever possible (Hossain 2005, 51). This practice was evident in my own field sites and these small-scale demands placed upon my assistants were inherently tied up with this social practice. The requests for small favors were, to a large extent, symbolic. The willingness to share their good fortune provided clear evidence that these individuals were valuable members of the community who would support friends and family where they could. Failure to manage these demands effectively could not only lead to resentments and jealousies in the short term-and in some cases they did — but also to the assistant's exclusion from future relationships of reciprocity within their community.

In addition to these everyday pressures, larger-scale requests regularly emerged as a result of my assistants' relationship with a "rich patron." These were particularly apparent in Hassan's case given that he worked with me for 
an extended period of time, but they were by no means limited to him alone. The most disruptive of these problems for Hassan revolved around his engagement and eventual marriage to his girlfriend. When I first met Hassan, he had been in a relationship with his girlfriend for two years and they had an 18-month-old child. Hassan had wanted to hold off on the marriage until he had established a small ice-cream business in his village, and this was not deemed unreasonable by either family. However, as the date of my departure approached, Hassan's family began to insist upon the marriage, and according to local gossip, their reasoning was that he should take advantage of the fact that I was still around in expectation of a substantial wedding "gift." Even more problematic than the increased pressure from Hassan's family, however, were the more opportunistic actions of the bride's family. Prior to my arrival in Kenya when the match had initially been discussed, the dowry had been extremely modest and affordable for Hassan. However, ten months later, as I was due to leave Kenya, the bride's father changed the sum of the dowry. He claimed that Hassan's wealth and status had increased since the initial discussions and that he could now afford to provide more. Thus, my presence and association with Hassan, however unintentionally, was extremely intrusive and disruptive. Not only was he pressured to marry perhaps sooner than he would have wished, but he was also required to pay a far larger dowry. I felt obliged to offer some financial assistance for my part in the issue, and reluctantly offered a small gift in addition to his usual salary. However, I was deeply resentful of being taken advantage of in this way and angered by the position I had been put in, creating a rift between myself and Hassan.

In addition to these issues regarding his marriage, Hassan's role and responsibilities within his family and among his friendship group also underwent perceptible changes over the course of the research, and he was put under increasing pressure to mobilize significant financial resources for various reasons. From providing his brother with 50,000 shillings to travel to Dubai for work, to finding 10,000 shillings to bail a friend out of jail, from assisting a cousin flee to Uganda after escaping police custody, to helping his sister-in-law set up a sewing business, Hassan became the go-to person for resolving problems among family and friends. While he did take pride in his role as protector and confidant, he also conveyed to me on a number of occasions that it caused him a great deal of worry and stress. His family and friends did not fully understand his relationship with me and believed that it was relatively easy for him to extract substantial sums as "gifts" rather than as loans or advances on his usual pay. He was also aware of my own reticence to advance his wages to such an extent, particularly when he would not receive any of the money himself. Not only were the sums being demanded excessive, but they raised a number of ethical questions. Knowing that Hassan had financial 
obligations to his girlfriend and their child, was it responsible for me to give such a substantial advance when the money would be given to someone else? Would the loan be regarded as supplementary to regular earnings, as some other smaller advances had been? Was it my place to advise Hassan on how to save some of his regular salary or, as Malony and Hammett (2007) note, would this be overly paternalistic? What sort of precedent would it set both for myself and for other researchers if I were to acquiesce to these requests for money? Thus, at times, Hassan was very much caught in the middle; his family's and friends' demands on the one hand would put a strain on his relationship with me, but on the other, his failure to try to meet them would cause a rift between himself and them. As Malony and Hammett note, the "emotional and ethical dilemmas" presented by these financial issues "can weigh heavily on the researcher" $(2007,289)$, but we should not forget that they also weigh heavily upon our assistants as well, and perhaps even more so.

Associations with researchers can also interrupt broader social relationships and can unsettle the assistant in a number of ways. In my own research, for example, assistants tended to place the burden of responsibility for the safe and successful progress of the research entirely upon their own shoulders and would regularly lament the difficulties of negotiating particular settings. Hassan in particular faced long periods of time working away from his home, isolated from his social groups and family. All local fieldworkers asserted that they had encountered petty jealousies from others as their perceived status shifted through their relationship with a "rich" foreigner. Victor Turner encountered similar problems in his relationship with Muchona the Hornet, who, after buying a new suit with the cash gifts Turner had provided, was the object of much jealousy in his village and subjected to malicious gossip and slander by members of the community. Muchona soon discarded the suit and told Turner, "This is the last time we can speak about customs together. Can't you hear the people talking angrily in the village shelter?" (V. Turner 1967, 147-48).

My assistants were also the targets of local gossip that affected their personal relationships, and it was not uncommon for the content of this gossip to be shaped by gender dynamics. Hassan, for example had to travel back to Nairobi from Nakuru when rumors of our imminent marriage pervaded his village back home and caused a blazing row between him and his girlfriend. Local rumors could also assume more sinister overtones, and assistants on occasion faced the same potentially dangerous accusations and suspicions to which I was subject, namely, that they were assisting ICC investigators. Moreover, these dangerous rumors were not bound to the temporal confines of the research. Indeed, while the researcher can walk away from the field at the end of the research, the assistant has to "live with his involvement in our project ... long after our fieldwork [is] complete" (Middleton and Pradhan 
2014, 370). For example, about a year after leaving the field, I had a Facebook message from my assistant who had worked with us for six weeks in Nakuru. In the message, he explained that a friend had begun to spread rumors around his village that he had brought an ICC investigator to the area and had worked with her to bring Kenyans to The Hague. He was concerned by how far the rumors had spread and what the consequences might be, saying that he no longer knew who was his friend, and who his enemy. The situation resolved itself over the subsequent days and he reassured me that he no longer felt threatened in the village, that the accusations had been borne out of a personal grudge and had not spread far. However, I remained concerned that the ethical challenges of my research were continuing in my absence. While I made various efforts at quelling the rumors from a distance - for example, by sending copies of my research permit and student registration to him, calling other contacts in Nakuru to ask them about the situation and to persuade them to try to quell the rumors - I realized that I was, to a large extent, powerless to help. While there has been an emerging trend in recent scholarship to acknowledge the physical and emotional challenges of fieldwork for the researcher, we often fail to pay sufficient attention to those faced by others associated with our research, and consequently, have few strategies in place to minimize the potential negative impacts of their involvement.

\section{Conclusion}

Recent scholarship has demonstrated an increasing interest in understanding the micro-level dynamics of political violence and conflict, and more local level empirical research is being carried out in these contexts. However, despite this shift, scholarship addressing the practicalities, the realities, and the methodological and ethical challenges of carrying out such research remains somewhat limited, and further reflection is needed. Indeed, there is a marked tendency for scholars to write out some of the methodological complexities of their fieldwork for fear of disciplinary criticism. This is not only unhelpful in terms of an honest exposition and engagement with the realities of field research, but it also obscures some of the implicit biases of the knowledge we produce. A key victim of this act of silencing is the figure of the research assistant. These individuals are often vital to the safe and smooth progression of the research. They open up avenues of access to outsider researchers through their social networks and contacts, while simultaneously allaying the almost inevitable suspicions regarding the researcher's intent; they facilitate trust-relationships among local communities and research subjects that allows sensitive topics to be explored; and they offer invaluable advice and strategies for ensuring the safety of all involved in the research. Conflict research is 
dependent upon these figures and failing to acknowledge their role amounts to a persistent "hidden colonialism" (Sanjek 1993, 13) in conflict research.

Nevertheless, the presence of research assistants also invokes certain biases in the knowledge that we produce and, as Cons states, "personal histories that at first sight would appear beyond the pale of ethnography proper can become constitutive of the field itself - often in ways unforeseen at the onset of the working relationship" (2014, 377). Assistants' positionalities can just as easily close off avenues of access and sources of information as they can open up others, and researchers must reflect honestly upon what stories they are able to tell, given how access was achieved. More than this, however, their advice with regard to safety and security is intimately entangled with the complex social dynamics of the field setting. Researchers can easily become caught up in the politics of fear that pervades conflict settings, and it becomes difficult, if not impossible, to accurately distinguish legitimate security concerns and advice from subjective and prejudiced perspectives. Researcher emotions, and assistants' roles in constructing these emotions, must be written into our academic accounts if we are to understand the limitations of our research. Finally, while attention is often afforded to the challenges of fieldwork for researchers, we seldom reflect upon the difficulties faced by our assistants. Our presence almost certainly disrupts their relationships and social positions, and we must be far better attuned to these dynamics in order to minimize any negative impacts. Thus, silencing the research assistant not only does a disservice to the extent of their influence over our research - in both its positive and negative manifestations - but it also prevents an honest, open, and fundamentally important discussion of how we can collaborate with these figures in a more ethical manner.

\section{Acknowledgments}

The author would like to thank Mateja Celestina and the three anonymous reviewers for their thoughtful comments on earlier drafts of this article. Any remaining errors are, of course, the author's responsibility.

\section{Declaration of Conflicting Interests}

The author declared no potential conflicts of interest with respect to the research, authorship, and/or publication of this article.

\section{Funding}

The author disclosed receipt of the following financial support for the research, authorship, and/or publication of this article: The research underpinning this article was carried out as part of author's PhD studies, with the support of the Aberystwyth Postgraduate Research Scholarship. 


\section{Notes}

1. There are a few notable exceptions to this, including Whyte (1955); Hapke and Ayyankeril (2001); Scott, Miller, and Lloyd (2006); Yeh (2006); Turner (2010); and Malony and Hammett (2007).

2. See, e.g., Middleton and Cons (2014a); also Angela Caretta (2015), Deane and Stevano (2016), and MacKenzie (2016).

3. The rising interest in violent contexts has led to a substantial body of literature that addresses field research in difficult and dangerous settings. Key texts in this scholarship include Belousov et al. (2007); Lee (1995); Mazurana, Jacobsen, and Gale (2013); Rodgers (2007); Sluka (1995); and Smyth and Robinson (2001).

4. All names are pseudonyms.

5. Crick (1992, 177); Nita Kumar (1992) similarly notes that the "dividing lines" between informants, brothers and friends were broken down during her research. For further reflections on friendship in field research, see Grindal and Salamone (1995), Newbold (1992), and Powdermaker (1966).

6. See also Sluka (1995).

\section{References}

Ajwang', Robert O., and Laura Edmondson. 2003. "Love in the Time of Dissertations: An Ethnographic Tale." Qualitative Inquiry 9 (3): 466-80.

Angela Caretta, Martina. 2015. "Situated Knowledge in Cross-Cultural, CrossLanguage Research: A Collaborative Reflexive Analysis of Researcher, Assistant and Participant Subjectivities." Qualitative Research 15 (4): 489-505.

Barley, Nigel. 1983. The Innocent Anthropologist: Notes from a Mud Hut. London: British Museum Publications.

Belousov, Konstantin, Tom Horlick-Jones, Michael Bloor, Yakov Gilinskiy, Valentin Golbert, Yakov Kostikovsky, Michael Levi, and Dmitri Pentsov. 2007. "Any Port in a Storm: Fieldwork Difficulties in Dangerous and Crisis-Ridden Settings." Qualitative Research 7 (2): 155-75.

Berreman, Gerald D. 2012. "Behind Many Masks: Ethnography and Impression Management." In Ethnographic Fieldwork: An Anthropological Reader, 2nd ed., edited by Antonius C. G. M. Robben and Jeffrey Sluka, 153-74. Malden, MA: Wiley-Blackwell.

Brewer, John D. 1993. "Sensitivity as a Problem in Field Research: A Study of Routine Policing in Northern Ireland." In Researching Sensitive Topics, edited by Claire M Renzetti and Raymond M. Lee, 125-45. Newbury Park: Sage.

Campbell, Lisa M., Noella J. Gray, Zoe A. Meletis, James G. Abbott, and Jennifer J. Silver. 2006. "Gatekeepers and Keymasters: Dynamic Relationships of Access in Geographical Fieldwork." Geographical Review 96 (1): 97-121

Chavez, Christina. 2008. "Conceptualizing from the Inside: Advantages, Complications and Demands on Insider Positionality." The Qualitative Report 13 (3): 474-94.

Cons, Jason. 2014. "Field Dependencies: Mediation, Addiction and Anxious Fieldwork at the India-Bangladesh Border." Ethnography 15 (3): 375-93. 
Crick, Malcom. 1992. "Ali and Me: An Essay in Street-Corner Anthropology." In Anthropology and Autobiography, edited by Judith Okely and Helen Callaway 177. London: Routledge.

Deane, Kevin, and Sara Stevano. 2016. "Towards a Political Economy of the Use of Research Assistants: Reflections from fieldwork in Tanzania and Mozambique." Qualitative Research 16 (2): 213-28.

Gill, Hannah E. 2004. "Finding a Middle Ground between Extremes: Notes on Researching Transitional Crime and Violence." Anthropology Matters 6 (2): 1-9. Grindal, Bruce, and Frank Salamone, eds. 1995. Bridges to Humanity: Narratives on Anthropology and Friendship. Prospect Heights, IL: Waveland, 1995.

Hapke, Holly M., and Devan Ayyankeril. 2001. 'Of 'Loose' Women and 'Guides,' or, Relationships in the Field." Geographical Review 91 (2): 342-52.

Hoffman, Danny, and Mohammed Tarawalley Jr. 2014. "Frontline Collaborations: The Research Relationship in Unstable Places." Ethnography 15 (3): 291-310.

Holmberg, David. 2014. "Ethnographic Agency, Field Assistants and the Rise of Cultural Activism in Nepal." Ethnography 15 (3): 311-30.

Hossain, Shahadat. 2005. "Poverty, Household Strategies and Coping with Urban Life: Examining 'Livelihood Framework' in Dhaka city, Bangladesh.” Bangladesh eJournal of Sociology 2 (1): 45-52.

Jacobs, Bruce A. 2006. "A Case for Dangerous Fieldwork.” In The Sage Handbook of Fieldwork, edited by Dick Hobbs and Richard Wright, 157-68. London: Sage. Kovats-Bernat, Christopher J. 2002. "Negotiating Dangerous Fields: Pragmatic Strategies for Fieldwork amid Violence and Terror." American Anthropologist 104 (1): 1-15.

Kumar, Nita. 1992. Friends, Brothers and Informants: Fieldwork memories of Banaras. Berkeley: University of California Press, 1992.

Lee, Raymond, ed. 1995. Dangerous Fieldwork. Thousand Oaks, CA: Sage.

MacKenzie, Catrina A. 2016. "Filtered Meaning: Appreciating Linguistic Skill, Social Position and Subjectivity of Interpreters in Cross-Language Research." Qualitative Research 16 (2): 167-82.

Malony, Thomas, and Daniel Hammett. 2007. "The Friendly Financier: Talking Money with the Silenced Assistant." Human Organization 66 (3): 292-300.

Mazurana, Dyan, Karen Jacobsen, and Lacey Gale, eds. 2013. Research Methods in Conflict Settings: A View from Below. Cambridge: Cambridge University Press. Mertus, Julie. 2009. "Introduction: Surviving Field Research.” In Surviving Field Research: Working in Violent and Difficult Situations, edited by Chandra Lekha Sriram, John C. King, Julie A. Mertus, Olga Martin-Ortega, and Johanna Herman. London: Routledge.

Middleton, Townsend, and Jason Cons. 2014a. "Special Issue on Fieldwork(ers): Research Assistants, Researchers and the Production of Ethnographic Knowledge." Ethnography 15 (3).

Middleton, Townsend, and Jason Cons. 2014b. "Coming to Terms: Reinserting Research Assistants into Ethnography's Past and Present.” Ethnography 15 (3): 279-90. 
Middleton, Townsend, and Eklavya Pradhan. 2014. "Dynamic Duos: On Partnership and the Possibilities of Postcolonial Ethnography." Ethnography 15 (3): 355-74.

Newbold, Beverly. 1992. La Zandunga: Of Fieldwork and Friendship in Southern Mexico. Prospect Heights, IL: Waveland.

Nordstrom, Carolyn. 1997. A Different Kind of War Story. Philadelphia: University of Pennsylvania Press.

Norman, Julie. 2009. "Got Trust? The Challenge of Gaining Access in Conflict Zones.” In Surviving Field Research: Working in Violent and Difficult Situations, edited by Chandra Lekha Sriram, John C. King, Julie A. Mertus, Olga MartinOrtega, and Johanna Herman, 71-90. London: Routledge.

Powdermaker, Hortense. 1966. Stranger and Friend: The Way of an Anthropologist. New York: Norton.

Punch, Maurice. 1989. "Researching Police Deviance: A Personal Encounter with the Limitations and Liabilities of Fieldwork." British Journal of Sociology 40: 177-204.

Robben, Antonius C. G. M., and Carolyn Nordstrom. 1995. "Introduction: The Anthropology and Ethnography of Violence and Sociopolitical Conflict." In Fieldwork under Fire: Contemporary Studies of Violence and Survival, edited by Carolyn Nordstrom and Antonius C. G. M. Robben, 1-23. Berkeley: University of California Press.

Rodgers, Dennis. 2007. "Joining the Gang and Becoming a Broder: The Violence of Ethnography in Contemporary Nicaragua." Bulletin of Latin American Research 26 (4): 444-61.

Sanjek, Roger. 1993. “Anthropology's Hidden Colonialism: Assistants and Their Ethnographers." Anthropology Today 9 (2): 13-18.

Scott, Steffanie, Fiona Miller, and Kate Lloyd. 2006. "Doing Fieldwork in Development Geography: Research Culture and Research Spaces in Vietnam." Geographical Research 44 (1): 28-40.

Sixmith, Judith, Margaret Boneham, and John E. Godring. 2013. "Accessing the Community: Gaining Insider Perspectives from the Outside." Qualitative Health Research 13 (4): 578-89.

Sluka, Jeffrey A. 1995. "Reflections on Managing Danger in Fieldwork: Dangerous Anthropology in Belfast." In Fieldwork under Fire: Contemporary Studies of Violence and Survival, edited by Carolyn Nordstrom and Antonius C. G. M Robben, 276-94. Berkeley: University of California Press.

Smyth, Marie. 2005. "Insider-Outsider Issues in Researching Violent and Divided Societies." In Researching Conflict in Africa: Insights and Experiences, edited by Elisabeth Porter, Gillian Robinson, Marie Smyth, Albrecht Schnabel, and Eghosa Osaghae. Tokyo: United Nations University Press.

Smyth, Marie, and Gillian Robinson, eds. 2001. Researching Violently Divided Societies: Ethical and Methodological Issues. New York: United Nations University Press.

Stacey, Judith. 1988. “Can There Be a Feminist Ethnography?" Women's Studies International Forum 77 (1): 21-27. 
Strocka, Cordula. 2008. "Participatory Research with War-Affected Adolescents and Youth: Lessons Learnt from Fieldwork with Youth Gangs in Ayacucho, Peru." In Years of Conflict: Adolescence, Political Violence and Displacement, Studies in Forced Migration, vol. 25, edited by Jason Hart, 255-76. New York: Berghahn Books.

Toros, Harmonie. 2008. "Terrorists, Scholars and Ordinary People: Confronting Terrorism Studies with Field Experiences." Critical Studies on Terrorism 1 (2): 279-92.

Thomson, Susan. 2010. "Getting Close to Rwandans since the Genocide: Studying Everyday Life in Highly Politicized Research Settings." African Studies Review 53 (3): 19-34.

Turner, Sarah. 2010. "Research Note: The Silenced Assistant. Reflections of Invisible Interpreters and Research Assistants." Asia Pacific Viewpoint 51 (2): 206-19.

Turner, Victor. 1967. The Forest of Symbols: Aspects of Ndembu Ritual. Ithaca, NY: Cornell University Press.

Whyte, William Foote. 1995 Street Corner Society: The Social Structure of an Italian Slum. Chicago: University of Chicago Press.

Widdowfield, Rebekah. 2000. "The Place of Emotions in Academic Research." Area 32 (2): 199-208.

Yeh, Emily T. 2006. “'An Open Lhasa Welcomes You': Disciplining the researcher in Tibet." In Doing Fieldwork in China, edited by Maria Heimer and Stig Thøgersen, 96-109. Honolulu: University of Hawaii Press.

\section{Author Biography}

Sarah Ann Jenkins is a research associate in the Centre for Trust, Peace and Social Relations at Coventry University. Her research lies at the intersection of African politics, democratisation and peace and conflict studies, and she is currently engaged in a study of electoral violence in sub-Saharan Africa. 